\title{
Ginsenoside Rg3 inhibition of vasculogenic mimicry in pancreatic cancer through downregulation of VE-cadherin/EphA2/MMP9/MMP2 expression
}

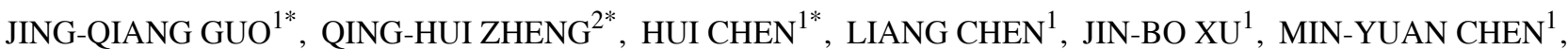 \\ DIAN LU ${ }^{1}$, ZHAO-HONG WANG ${ }^{1}$, HONG-FEI TONG ${ }^{1}$ and SHENGZHANG LIN ${ }^{1,3}$ \\ ${ }^{1}$ Department of Hepatobiliary-Pancreatic Surgery, The Second Affiliated Hospital, Wenzhou Medical University, \\ Wenzhou 325027; ${ }^{2}$ Guangxi Medical University, Nanning 530021; ${ }^{3}$ Department of Hepatobiliary-Pancreatic Surgery, \\ First Affiliated Hospital, Zhejiang University School of Medicine, Hangzhou 310003, P.R. China
}

Received March 11, 2014; Accepted May 13, 2014

DOI: $10.3892 /$ ijo.2014.2500

\begin{abstract}
Ginsenoside $\operatorname{Rg} 3$ ( $\operatorname{Rg} 3)$, a trace tetracyclic triterpenoid saponin, is extracted from ginseng and shown to have anticancer activity against several types of cancers. This study explored the effect of $\operatorname{Rg} 3$ on pancreatic cancer vasculogenic mimicry. Altered vasculogenic mimicry formation was assessed using immunohistochemistry and PAS staining and associated with the expression of vascular endothelial-cadherin (VE-cadherin), epithelial cell kinase (EphA2), matrix metalloproteinase (MMP)-2 and MMP-9. The effect of Rg3 on the regulation of pancreatic cancer vasculogenic mimicry was evaluated in vitro and in vivo. The data showed vasculogenic mimicry in pancreatic cancer tissues. In addition, the expression of VE-cadherin, EphA2, MMP-2 and MMP-9 proteins associated with formation of pancreatic cancer vasculogenic mimicry. Rg3 treatment reduced the levels of vasculogenic mimicry in nude mouse xenografts in vitro and in vivo, while the expression of VE-cadherin, EphA2, MMP-2 and MMP-9 mRNA and proteins was downregulated by $\mathrm{Rg} 3$ treatment in vitro and in tumor xenografts. In conclusion, ginsenoside $\mathrm{Rg} 3$ effectively inhibited the formation of pancreatic cancer vasculogenic mimicry by downregulating the expression of VE-cadherin, EphA2, MMP9 and MMP2. Further studies are required to evaluate ginsenoside $\operatorname{Rg} 3$ as an agent to control pancreatic cancer.
\end{abstract}

Correspondence to: $\mathrm{Dr}$ Shengzhang Lin, Department of Hepatobiliary-Pancreatic Surgery, First Affiliated Hospital, Zhejiang University School of Medicine, 79 Qingchun Road, Hangzhou 310003, P.R. China

E-mail:wzf21sz@163.com

${ }^{*}$ Contributed equally

Key words: vasculogenic mimicry, ginsenoside $\operatorname{Rg} 3$, pancreatic cancer, vascular endothelial-cadherin, matrix metalloproteinase

\section{Introduction}

Pancreatic cancer is a lethal disease with only a $6 \%$ of overall 5 -year survival rate. Surgical resection remains the only cure option, which improves the 5-year survival rate to $20 \%$; however, frequent recurrence is recorded after surgery (1). Most pancreatic cancer patients are diagnosed at advanced stages of the disease, making curable surgery impossible. During disease progression, the blood supply is necessary for tumor growth, invasion and metastasis $(2,3)$, thus, neoangiogenesis is the key for cancer development and progression. It was thought that formation of new blood vessels in tumor lesions depends on vascular endothelial cells. However, in 1999, Maniotis et al (4) reported that there was a ring-shaped loop interconnecting network from extracellular matrix and melanoma cells to facilitate neoangiogenesis in skin or liver metastasis. Under a scanning electron microscope, red cells were observed in this network. Both indocyanine green angiography and in vitro microinjection demonstrated that the networks are similar to the artery with vascular lumen tissue perfusion effects. This novel network, which is independent from endothelial cells, was referred to as vasculogenic mimicry (VM). The level of VM was associated with poor prognosis of patients (4). As a part of the classic tumor vascular endothelium-dependent complement, VM may provide a reasonable explanation of ineffective anti-angiogenesis therapy for cancer patients. VM has been observed in several other aggressive tumor types, such as laryngeal squamous cell carcinoma, ovarian cancer, breast cancer, osteosarcoma, astrocytoma and gallbladder cancer (5-12). Most recent studies have shown that vascular endothelial-cadherin (VE-cadherin), epithelial cell kinase (EphA2), and matrix metalloproteinase (MMPs) play a crucial role in VM formation (13-21). Thus, regulation of VM formation could be a novel cancer therapy strategy against human cancers, including pancreatic cancer.

Ginseng is an oriental medicine used for thousand years and possesses immunomodulatory, 'qi' and anti-aging effects (22). Ginsenoside $\operatorname{Rg} 3(\operatorname{Rg} 3)$ is a trace tetracyclic triterpenoid saponin extracted from ginseng and can induce tumor cell apoptosis, but inhibits tumor cell proliferation, adhesion, 
invasion and metastasis as well as tumor angiogenesis (23-29). $\operatorname{Rg} 3$ adjuvant therapy synergies the effects of chemotherapy drugs and enhances host immune function (23-29). Since the last decade, anti-angiogenesis therapy has been widely accepted as a means for tumor therapy, mainly to control the growth of vascular endothelial cells. However, in recent studies $(30,31)$, anti-angiogenesis therapy using angiostatin or endostatin to target endothelial cells showed to have little effect on regulating the progression of tumors with VM formation. This may be because VM does not involve endothelial cells, and thus does not respond to anti-angiogenesis therapy (30,31). Moreover, van der Schaft et al (32) reported that Anginex, TNP-470, and endostatin inhibit growth of vascular endothelial cells, but did not prevent melanoma cells to form VM. Further research on VM inhibition could yield a better antitumor activity (33). Indeed, Wang et al (34) demonstrated that $\mathrm{Rg} 3$ could inhibit tube-like structure formation in a human nasopharyngeal carcinoma cell line in vitro.

In this study, we assessed VM formation in pancreatic cancer tissues ex vivo and then investigated correlations between the expression of VE-cadherin, EphA2 and MMP protein and VM formation. In addition, we explored the effects of $\mathrm{Rg} 3$ on the regulation of VM formation in vitro and in vivo nude mouse xenografts.

\section{Materials and methods}

Patients and tissue specimens. A total of 117 patients with pancreatic cancer and 62 patients with benign pancreatic disease were recruited from The Second Affiliated Hospital, Wenzhou Medical University (Wenzhou, China) and First Affiliated Hospital, Zhejiang University School of Medicine, (Hangzhou, China) between 2007, and 2012. Our institutional review board approved this study and a written informed consent form was obtained from each patient. All patients were diagnosed histologically and confirmed by an experienced pathologist. Paraffin-embedded tissue specimens were retrieved from the Pathology Department for immunohistochemistry and PAS staining.

Immunohistochemistry. Paraffin sections (4- $\mu \mathrm{m}$ thick) of pancreatic tissue specimens were prepared for immunohistochemistry. Briefly, the sections were heated in an oven at $65^{\circ} \mathrm{C}$ for $60 \mathrm{~min}$ and then deparaffinized in xylene and rehydrated in series of ethanol. The sections were then subjected to high boiling antigen retrieval in a pressure cooker and washed with phosphate-buffered saline (PBS) 3 times, 5 min each. Next, the sections were treated with $3 \%$ hydrogen peroxide for $20 \mathrm{~min}$ at room temperature to inactivate peroxidase and then rinsed with PBS and blocked subsequently with 5\% normal goat serum. Next, the sections were incubated with the primary antibody (i.e., the anti-CD31 at a dilution of 1:100, antiVE-cadherin at a dilution of 1:100, anti-EphA2 at a dilution of 1:50, anti-MMP-2 at a dilution of 1:100, or anti-MMP-9 at a dilution of 1:200) in a moist chamber overnight at $4^{\circ} \mathrm{C}$. A mouse monoclonal anti-CD31 antibody was purchased from Santa Cruz Biotechnology (Santa Cruz, CA, USA), mouse anti-MMP-2 and rabbit anti-VE-cadherin antibodies were purchased from Abgent (San Diego, CA, USA), a mouse anti-EphA2 was purchased from R\&D Systems (Boston, MA,
USA), and a rabbit anti-MMP-9 was obtained from Abcam (Cambridge, MA, USA). The next day, the sections were rinsed with PBS for three times and further incubated with a horseradish peroxidase (hRP)-conjugated secondary antibody (Beyotime Biotechnology, Haimen, China) at room temperature for $30 \mathrm{~min}$. Then, peroxidase labeling was developed by incubating the sections with diaminobenzidine tetrahydrochloride (DAB) solution for $3 \mathrm{~min}$, counterstained with hematoxylin, and then mounted and evaluated under a light microscope (Olympus BX51, Japan). Negative control sections were incubated with PBS instead of the specific primary antibody.

CD31 and PAS double-staining. Sections were first stained for CD31 immunohistochemistry and then stained with $0.5 \%$ periodic-acid-Schiff (PAS) solution for $10 \mathrm{~min}$ and rinsed with distilled water for 2-3 min. In a dark chamber, these sections were further stain treated with Schiff solution for $15 \mathrm{~min}$ and then rinsed with distilled water, dehydrated and mounted. Normal pancreatic tissues were used as a positive control. CD31 staining was used to visualize blood vessels, helping to distinguish the PAS-positive network of VM from endothelium-lined microvessel. PAS staining was used to identify matrix-associated vascular channels in pancreatic cancer tissues. Levels of VM were quantified according to a previous study (35). Specifically, the stained sections were scored under a microscope for 10 randomly chosen fields at $\mathrm{x} 400$. The vessels lined by endothelial cells, regardless of the presence of basement membrane, were counted as endothelium-dependent vessels. In contrast VM was defined as enclosed pancreatic cancer cells with PAS-positive material. The average number of VM channels was determined for each section.

Cell line and culture. Human pancreatic cancer cell lines (PANC-1 and SW1990) were obtained from Shanghai Cell Bank (Shanghai, China). Human pancreatic cancer cell lines (Bxpc-3 and MiaPaCa-2) were obtained from American Type Culture Collection (Manassas, VA, USA). All the cell lines were cultured in Dulbecco's modified Eagle's medium (DMEM) supplemented with 10\% fetal bovine serum (FBS), $100 \mathrm{U} / \mathrm{ml}$ penicillin, and $100 \mu \mathrm{g} / \mathrm{ml}$ streptomycin (all from Gibco-BRL/Invitrogen, Grand Island, NY, USA) at $37^{\circ} \mathrm{C}$ in a humidified incubator with $5 \% \mathrm{CO}_{2}$. Cells were passaged at $70-80 \%$ confluence. For $\mathrm{Rg} 3$ treatment, ginsenoside $\mathrm{Rg} 3$ standard with a purity $\geq 98 \%$ was purchased from Shanghai Bo Yun Biotechnology (Shanghai, China) and dissolved in dimethylsulfoxide (DMSO, Invitrogen, Carlsbad, CA, USA) at the concentration of $200 \times 10 \mu \mathrm{mol} / 1$. The solution was then diluted with DMEM to the desired concentration before use. The cells were grown overnight and then treated with $\mathrm{Rg} 3$ at different concentrations, while the medium containing $0.1 \%$ DMSO served as a negative control.

Tumor cell three-dimension culture and PAS staining. Three-dimensional type I collagen gels were prepared as described previously (19). A total of $25 \mu \mathrm{l}$ of rat-tail type I collagen (average $3 \mathrm{mg} / \mathrm{ml}$; from BD Biosciences, Bedford, MA, USA) were dropped onto 18 -mm glass coverslips in 12-well culture plates and polymerized $5 \mathrm{~min}$ at room temperature. After washing with PBS for $5 \mathrm{~min}, 5 \times 10^{5}$ tumor cells were seeded onto the three-dimensional type I collagen gel and treated with $\mathrm{Rg} 3$ 
at $0,25,50,100$ and $200 \mu \mathrm{mol} / 1$ for $72 \mathrm{~h}$ to analyze the ability of tumor cells to form VM. At the end of the experiments, the cells were fixed with $4 \%$ formaldehyde in PBS for $10 \mathrm{~min}$ and washed with PBS. The cells were then stained with PAS.

Animal experiments. A protocol of animal experiments was approved by Wenzhou Medical University Experimental Animal Center (Wenzhou, China). Briefly, 28 six-week old, male, athymic, BaLB/c nu/nu mice were purchased from the Shanghai Cancer Institute (Shanghai, China) and were maintained in a specific-pathogen-free environment in our animal center. The housing temperature was maintained at $25 \pm 1^{\circ} \mathrm{C}$ and relative humidity was controlled at $40-60 \%$. SW-1990 cells in the log-growth phase were detached with $0.05 \%$ trypsin and re-suspended with serum-free culture medium. The cells were then subcutaneously injected into the right flank with $5 \times 10^{6}$ SW-1990 cells per injection (36). Three days later, the mice were randomly assigned into control and ginsenoside $\mathrm{Rg} 3$ groups. The control mice $(n=7)$ were treated by intraperitoneal injection with $0.9 \%$ sodium chloride once every other day and three groups of ginsenoside $\mathrm{Rg} 3$-treated mice ( $\mathrm{n}=7$, each group) were intraperitoneally injected with 5,10 or $20 \mathrm{mg} / \mathrm{kg} /$ day ginsenoside, respectively. The treatment was continued every other day for 28 days. At the end of the experiments, the mice were sacrificed and tumor xenografts were resected, weighed and then fixed in $10 \%$ neutral buffered formalin and embedded in paraffin. Paraffin-embedded tissue blocks were cut into $4-\mu \mathrm{m}$ thick sections for immunohistochemistry and PAS staining.

$R N A$ isolation and $q R T-P C R$. Total cellular RNA from cell lines or tissues was isolated using TRIzol reagent (Invitrogen) according to the manufacturer's protocol. RNA was then reverse transcribed into cDNA using RevertAid First Strand cDNA Synthesis Kit (Fermentas, South Logan, UT, USA) according to the manufacturer's instructions. PCR amplification was performed using gene-specific primers (Table I) in a Roche real-time PCR machine in a total of $10 \mu \mathrm{l}$ reaction mixture that contained $1 \mu \mathrm{l} \mathrm{cDNA,} 5 \mu \mathrm{l} \mathrm{SYBR-Green} \mathrm{real-time} \mathrm{PCR} \mathrm{master}$ mix-plus (Toyobo, Japan), and $1 \mu 1$ primer each. The PCR conditions were set to an initial denaturation at $95^{\circ} \mathrm{C}$ for $90 \mathrm{sec}$ and 40 cycles of $95^{\circ} \mathrm{C}$ for $5 \mathrm{sec}, 60^{\circ} \mathrm{C}$ for $30 \mathrm{sec}$, and $72^{\circ} \mathrm{C}$ for $45 \mathrm{sec}$. GAPDH mRNA was used as a loading control. The experiments were performed in triplicates and repeated three times with independently derived samples. The data were analyzed using LightCycler 480 software (Roche, Switzerland).

Protein extraction and western blot analysis. Total cellular protein was extracted from cultured cells or tissue samples using a radioimmunoprecipitation assay (RIPA) buffer (Pierce, Rockford, IL, USA). After centrifugation at 12,000 x $\mathrm{g}$ for $20 \mathrm{~min}$ at $4^{\circ} \mathrm{C}$, the supernatant was collected and protein concentration was measured using the BCA Protein Assay Kit (Pierce) according to the manufacturer's instructions. Samples containing $40 \mu \mathrm{g}$ of protein from cell culture and $60 \mu \mathrm{g}$ of protein from tissue samples were subjected to $8 \%$ sodium dodecyl sulfate-polyacrylamide gel electrophoresis (SDS-PAGE) and transferred electrophoretically on to polyvinylidene fluoride (PVDF) membranes (Invitrogen). Equal protein loading was confirmed by Coomassie staining (Bio-Rad, Hercules, CA, USA) of the gel. After blocking with
Table I. Primer sequences and PCR product size.

Size of PCR

Gene Primers products (bp)

\begin{tabular}{llc}
\hline VE-cadherin & $\begin{array}{l}\text { 5'-aagcgtgagtcgcaa-3' } \\
\text { 5'-tctccaggtttcgc-3' }\end{array}$ & 179 \\
EphA2 & 5'-gagggcgtcatctccaaata-3' & 236 \\
& 5'-tcagacaccttgcagaccag-3' & \\
MMP-2 & 5'-gatacccctttgacggtaagga-3' & 112 \\
& 5'-ccttctcccaaggtccatagc-3' & \\
MMP-9 & 5'-ttgacagcgacaagaagtgg-3' & 179 \\
& 5'-gccattcacgtcgtccttat-3' & \\
GAPDH & 5'-gagtcaacggatttggtcgt-3' & 238 \\
& 5'-ttgattttggagggatctcg-3'
\end{tabular}

$5 \%$ bovine serum albumin (BSA), the membrane was incubated with the primary antibodies followed by incubation with the secondary antibodies. Immunoreactivity was detected using the Enhanced Chemiluminescence Kit (Pierce) according to the manufacturer's instructions. Each experiment was repeated three times and the data were analyzed using AlphaEaseFC 4.0 software (San Leandro, CA, USA).

Statistical analysis. Data are summarized as mean \pm SD. Statistical analysis was performed using SPSS 17.0. (SPSS, Chicago, IL, USA) and differences between ginsenoside Rg3 and DMSO-treated (control) groups were analyzed with an unpaired Student's t-test or ANOVA analysis. Association of clinicopathological data from pancreatic cancer cases or between groups was analyzed by the $\chi^{2}$ test. $p<0.05$ was considered statistically significant.

\section{Results}

Induction of VM in pancreatic cancer tissues. Endothelial structure has stained brown by an anti-CD31 antibody, while VM pipe and extracellular matrix were stained red color by PAS staining. Based on CD31 and PAS staining, CD31-negative, PAS-positive vascular-like structures were VM. In these 117 cases of pancreatic cancer tissues, VM was shown for $71.79 \%(84 / 117)$ of pancreatic cancer cases, while all 53 benign pancreatic disease cases had no VM $(0 \%, 0 / 53)$ (Fig. 1).

Association of VM with the expression of VE-cadherin, EphA2, MMP-2 and MMP-9 proteins in pancreatic cancer tissues. We then assessed the expression of VE-cadherin, EphA2, MMP-2 and MMP-9 proteins in pancreatic tissues for association with VM. The data showed that expression of these proteins was associated with VM formation of pancreatic cancer tissues compared to those of benign pancreatic tissues (Fig. 2 and Table II).

Different levels of VM in pancreatic cancer cell lines. We then detected VM in pancreatic cancer cell lines using 3D cultures and found that SW-1990 cells formed circular channel features, while Panc-1, Bxpc-3 and MiaPaCa-2 did not (Fig. 3). 

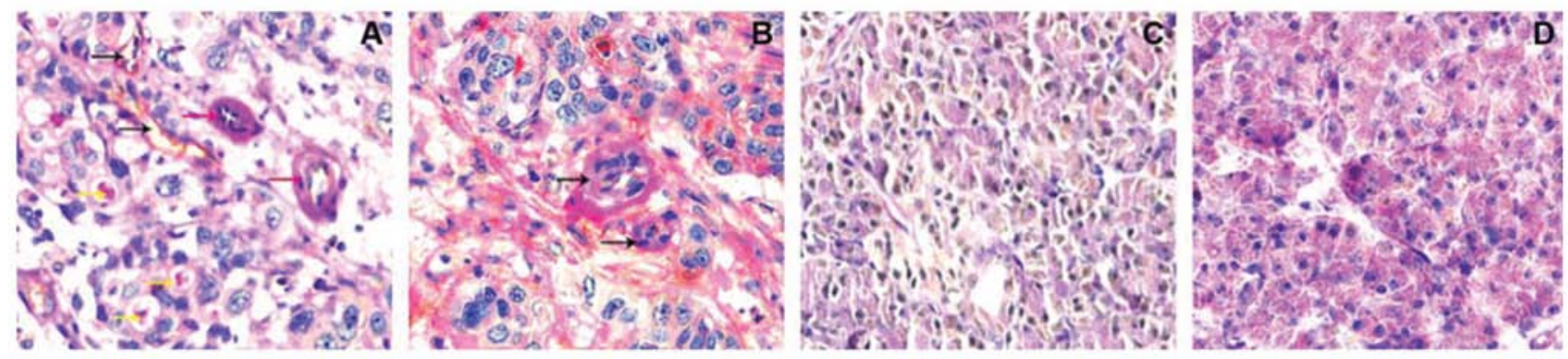

Figure 1. Induction of vasculogenic mimicry in pancreatic cancer tissues. (A and B) Double staining of CD31/PAS in pancreatic cancer tissues. Vascular mimicry is shown by red arrows. PAS-positive substances lined these channels and formed basement membrane-like structures (vascular mimicry). Pancreatic acinar cells are purple granules or secretory vesicles (yellow arrows) and CD31-positive (black arrows) (x400). (C and D) Double staining of CD31/PAS in benign pancreatic disease. There is no dyed purple extracellular matrix-like material (magnification, $\mathrm{x} 400$ ).
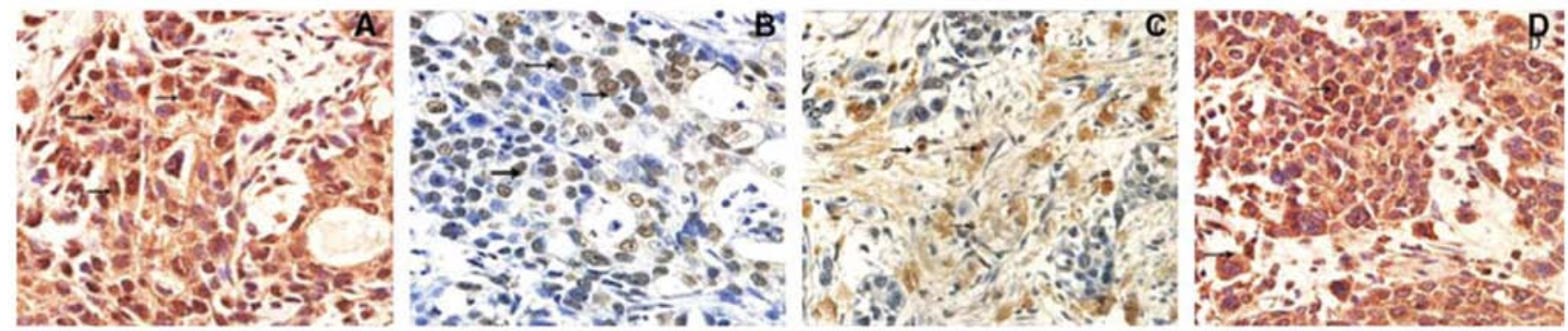

Figure 2. Expression of VE-cadherin, EphA2, MMP-2 and MMP-9 proteins in pancreatic cancer tissues associated with vascular mimicry formation. (A) Expression of VE-cadherin protein in vascular mimicry (black arrow). (B) Expression of EphA2 protein in vascular mimicry (black arrow). (C) Expression of MMP-9 protein in vascular mimicry (black arrow). (D) Expression of MMP-2 protein in vascular mimicry (black arrow) (magnification, $\mathrm{x} 400$ ).
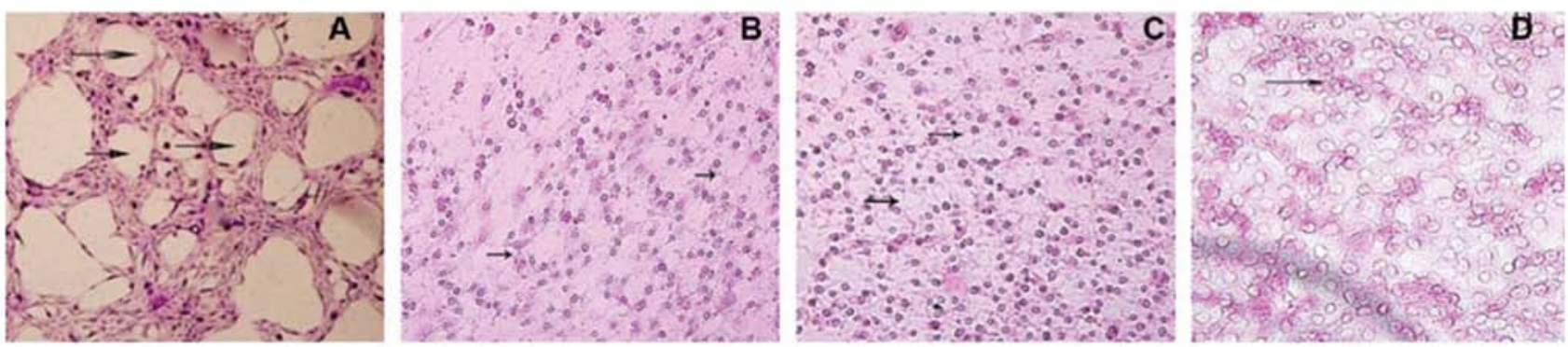

Figure 3. Different levels of vasculogenic mimicry in four different pancreatic cancer cell lines (SW-1990, Panc-1, Bxpc-3 and MiaPaCa-2). (A) SW-1990 cells formed circular channel features in a 3D environment following $72 \mathrm{~h}$ of culture (black arrow). (B and C) Bxpc-3 and MiaPaCa-2 cells in 3D culture for $72 \mathrm{~h}$. The tumor cells connected filaments (black arrows). (D) Panc-1 cells in 3D culture for $72 \mathrm{~h}$. The tumor cells showed overlap growth (black arrows) (magnification, $\mathrm{x} 200$ ).

Effects of ginsenoside Rg3 on the regulation of VM levels in vitro. Since SW-1990 cells can form VM in a 3D culture, we utilized this cell line for further study of the effects of $\mathrm{Rg} 3$ on the regulation of VM formation in vitro. We found that SW-1990 cells treated with $25 \mu \mathrm{mol} / 1$ ginsenoside $\mathrm{Rg} 3$ began to form irregular VM, while $50 \mu \mathrm{mol} / 1$ concentrations led more SW-1990 cells to form irregular vascular mimicry. Ginsenoside Rg3 (200 $\mu \mathrm{mol} / \mathrm{l})$ totally inhibited SW-1990 cells to form VM (Fig. 4). We then analyzed the expression of VE-cadherin, EphA2, MMP-2 and MMP-9 protein and mRNA in SW-1990 cells. We found that ginsenoside Rg3 dosedependently reduced expression of these proteins in SW-1990 cells (p<0.05, Fig. 5A) and levels of their mRNA (Fig. 5B).
Table II. Association of VE-cadherin, EphA2, MMP-2 and MMP-9 proteins with VM.

\begin{tabular}{lccc}
\hline & VM (+) & VM (-) & p-value \\
\hline VE-cadherin (+) & 78 & 2 & $<0.05$ \\
VM (-) & 0 & 4 & \\
EphA2 (+) & 68 & 8 & $<0.05$ \\
EphA2 (-) & 1 & 7 & \\
MMP-2 (+) & 77 & 4 & $<0.05$ \\
MMP-2 (-) & 0 & 3 & \\
MMP-9 (+) & 70 & 3 & $<0.05$ \\
MMP-9 (-) & 3 & 8 & \\
\hline
\end{tabular}



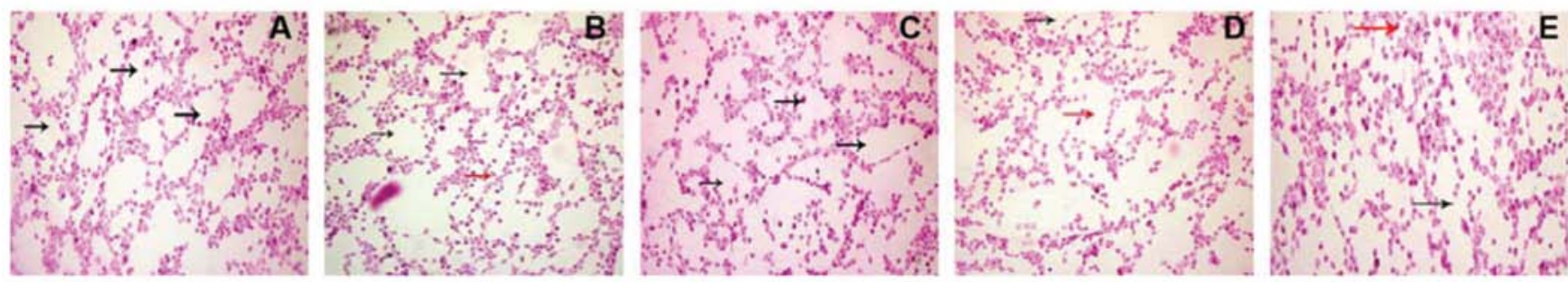

Figure 4. Effect of ginsenoside Rg3 on the regulation of vasculogenic mimicry levels in pancreatic cancer SW-1190 cells in a 3D collagen I culture. Cells were treated with different concentrations of ginsenoside Rg3. (A) Ginsenoside $\operatorname{Rg} 3(0 \mu \mathrm{mol} / \mathrm{l})$, the formation of vasculogenic mimicry (black arrow) (B) Ginsenoside $\operatorname{Rg} 3$ ( $25 \mu \mathrm{mol} / \mathrm{l})$ began to form irregular vascular mimicry (black arrows show vascular mimicry; red arrows show irregular vascular mimicry). (C) Ginsenoside Rg3 (50 $\mu \mathrm{mol} / \mathrm{l})$ formed irregular vascular mimicry (black arrow). (D) Ginsenoside Rg3 (100 $\mu$ mol/l) formed irregular vascular mimicry (black arrow) or failed to form VM channels (red arrow). (E) Ginsenoside Rg3 (200 $\mu \mathrm{mol} / \mathrm{l})$ totally inhibited VM channel formation (black arrow) or tumor cells grew densely (red arrow). Magnification, x200.

A

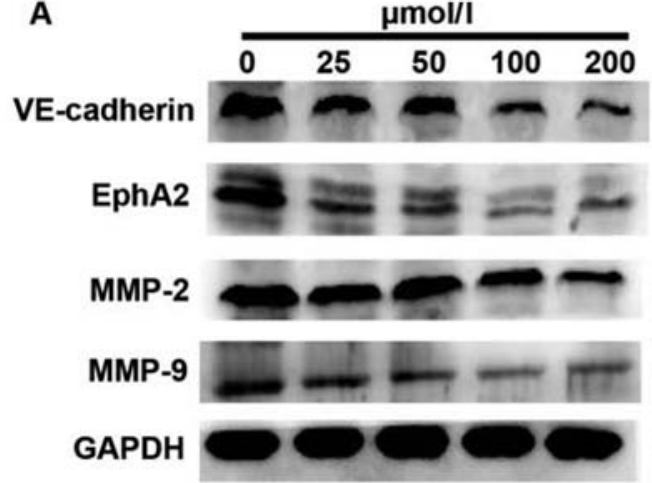

B

$-88 \mathrm{kDa}$

$-130 \mathrm{kDa}$

$-72 \mathrm{kDa}$

$-92 \mathrm{kDa}$

$-36 \mathrm{kDa}$

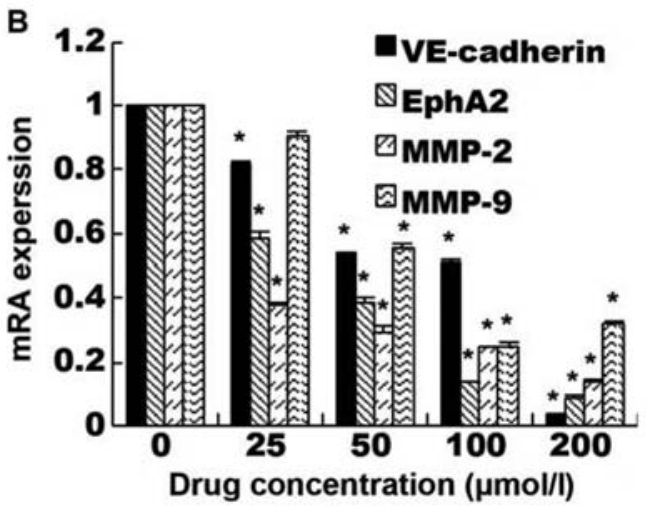

Figure 5. Effects of ginsenoside Rg3 on the regulation of VE-cadherin, EphA2, MMP-2 and MMP-9 expression in vitro. (A) Expression of VE-cadherin, EphA2, MMP-2 and MMP-9 proteins was analyzed using western blot analysis. Rg3 significantly reduced the levels of these proteins (p<0.05). (B) qRT-PCR. The duplicate samples were subjected to RNA isolation and qRT-PCR analysis. ${ }^{*} \mathrm{p}<0.05$.

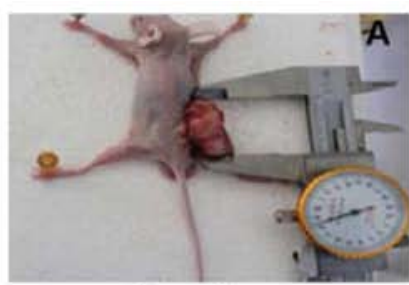

$0 \mathrm{mg} / \mathrm{kg}$

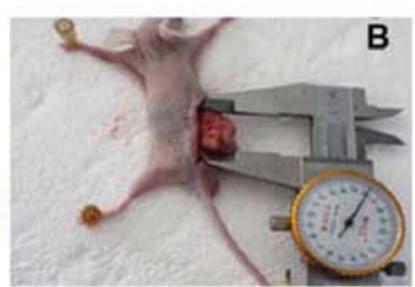

$5 \mathrm{mg} / \mathrm{kg}$

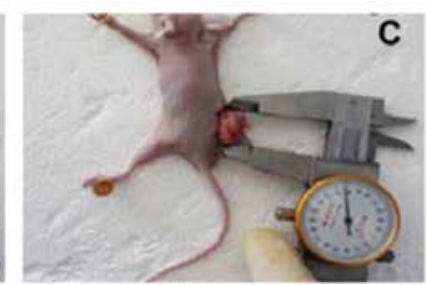

$10 \mathrm{mg} / \mathrm{kg}$

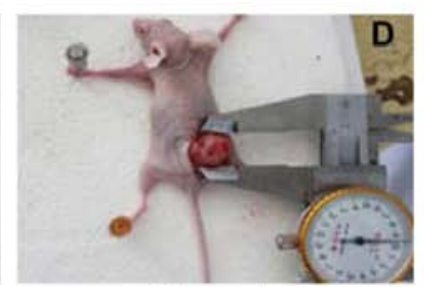

$20 \mathrm{mg} / \mathrm{kg}$

Figure 6. Effect of Ginsenoside $\operatorname{Rg} 3$ on the regulation of pancreatic cancer SW-1990 cell xenografts in nude mice.

Effects of ginsenoside Rg3 on the regulation of tumor growth and VM formation in vivo. Next, we assessed the effects of Ginsenoside Rg3 on the regulation of tumor growth and VM formation in vivo in a nude mouse model. The data showed that Ginsenoside Rg3 dose-dependently suppressed tumor growth in nude mice (Fig. 6 and Table III). Similarly, ginsenoside Rg3 treatment of mice dose-dependently suppressed VM formation (Fig. 7 and Table IV).

Effects of ginsenoside $\mathrm{Rg} 3$ on the regulation of gene expression in tumor xenografts in vivo. Ginsenoside Rg3 treatment
Table III. Effect of ginsenoside $\mathrm{Rg} 3$ on regulation of pancreatic cancer cell xenograft growth in nude mice.

\begin{tabular}{ccc}
\hline Treatment & Tumor weight $(\mathrm{g})$ & Tumor volume $\left(\mathrm{mm}^{3}\right)$ \\
\hline $0 \mathrm{mg} / \mathrm{kg}$ & $1.48 \pm 0.130$ & $662.78 \pm 12.91$ \\
$5 \mathrm{mg} / \mathrm{kg}$ & $1.11 \pm 0.455$ & $414.64 \pm 13.46^{\mathrm{a}}$ \\
$10 \mathrm{mg} / \mathrm{kg}$ & $0.95 \pm 0.317$ & $351.43 \pm 20.65^{\mathrm{a}}$ \\
$20 \mathrm{mg} / \mathrm{kg}$ & $0.58 \pm 0.236^{\mathrm{a}}$ & $300.33 \pm 14.71^{\mathrm{a}}$ \\
\hline
\end{tabular}

${ }^{\mathrm{a}} \mathrm{p}<0.05$ 

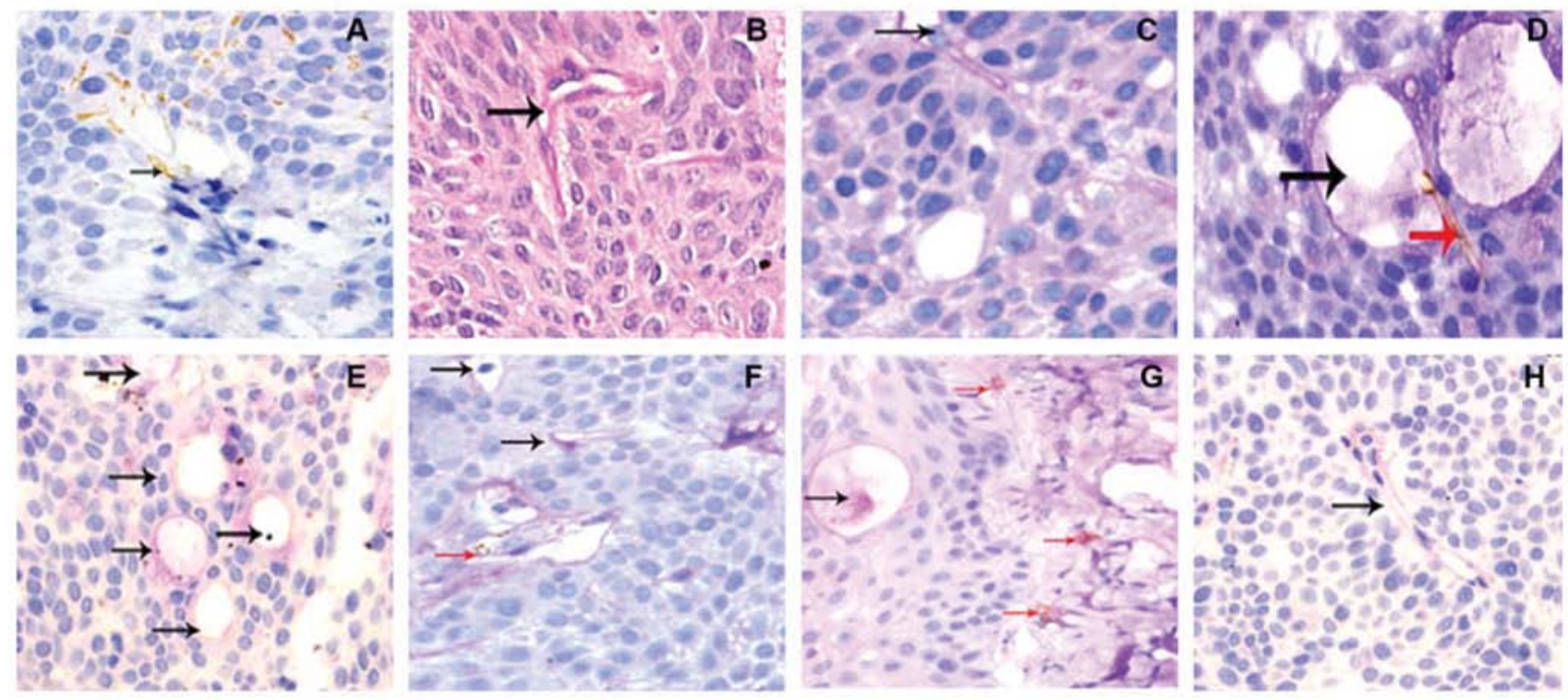

Figure 7. Effect of different concentrations of ginsenoside Rg3 on vasculogenic mimicry formation in nude mouse xenografts. (A) CD31 staining. CD31-positive (black arrow). (B) PAS staining. PAS-positive (black arrow). (C) CD31/PAS double staining. Tumor cell vasculogenic mimicry (black arrow). (D) CD31/PAS double staining. CD31-positive (red arrow) and PAS-positive (black arrow). (E) RG3 treatment ( $0 \mathrm{mg} / \mathrm{kg}$ ). CD31/PAS double staining. PAS-positive (black arrow). (F) RG3 treatment $(5 \mathrm{mg} / \mathrm{kg}$ ). CD31/PAS double staining. CD31-positive (red arrow) and PAS-positive (black arrow). (G) RG3 treatment (10 mg/kg). CD31/PAS double staining. CD31-positive (red arrow) and PAS-positive (black arrow). (H) RG3 treatment (20 mg/kg). CD31/PAS double staining. PAS-positive (black arrow). Magnification, $\mathrm{x} 400$.

A

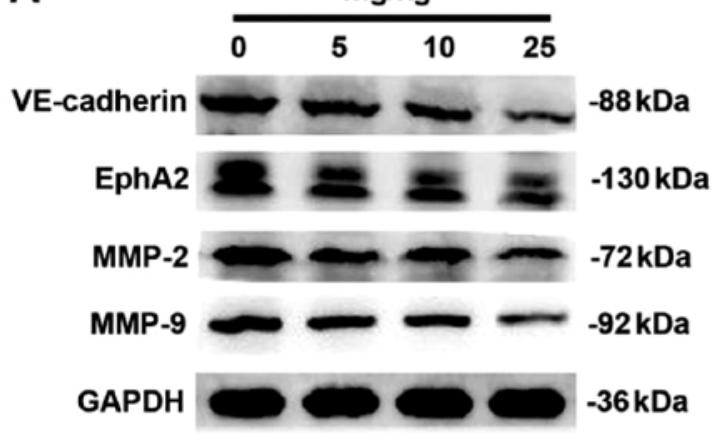

B

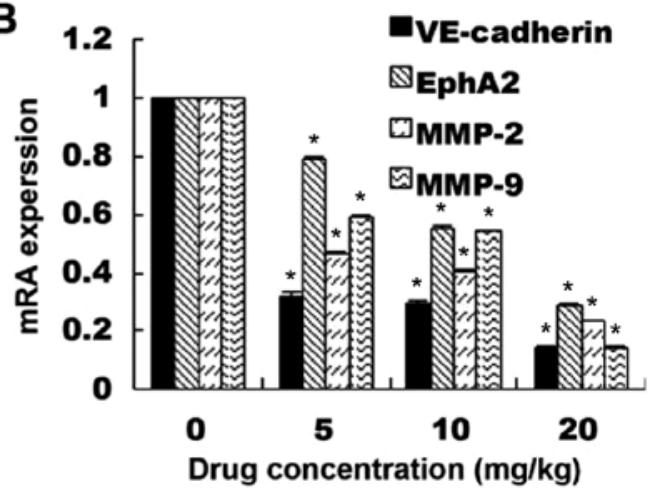

Figure 8. Effects of ginsenoside Rg3 on the regulation of VE-cadherin, EphA2, MMP-2 and MMP-9 protein expression in tumor xenografts in vivo. (A) Western blot analysis. (B) qRT-PCR. Tumor xenografts were resected from nude mice and subjected to western blot and qRT-PCR analysis.

Table IV. Effects of ginsenoside Rg3 on the regulation of tumor xenograft VM formation in vivo.

\begin{tabular}{rcc}
\hline & VM $(+)$ & p-value \\
\hline $0 \mathrm{mg} / \mathrm{kg}$ & $2.3 \pm 1.159$ & \\
$5 \mathrm{mg} / \mathrm{kg}$ & $1.6 \pm 0.843$ & 0.563 \\
$10 \mathrm{mg} / \mathrm{kg}$ & $0.5 \pm 0.572$ & 0.004 \\
$20 \mathrm{mg} / \mathrm{kg}$ & $0.3 \pm 0.483$ & 0.002 \\
\hline
\end{tabular}

of nude mice also showed a dose-dependent inhibition of VE-cadherin, EphA2, MMP-2 and MMP-9 proteins ( $\mathrm{p}<0.05$; Fig. 8A) and mRNA in pancreatic cancer cell xenografts (p<0.05; Fig. 8B).

\section{Discussion}

VM was first reported by Maniotis et al (4) in 1999 as a ring-shaped loop interconnecting network, which is made of extracellular matrix and melanoma tumor cells. This structure can transport erythrocytes and plays an important role in tumor progression. As a novel tumor microcirculation system, VM differs from classically described endotheliumdependent angiogenesis. In addition, VM has been observed in several other tumor types, such as laryngeal squamous cell carcinoma, ovarian cancer, breast cancer, osteosarcoma, astrocytoma and gallbladder cancer (5-10). Thus, more recently, VM has been targeted as a novel strategy to treat solid tumors $(32,37)$. However, not all tumor cells can form VM. Histologically, VM channels are patterned networks of interconnected loops of PAS-positive extracellular matrix 
formed by highly malignant melanoma cells, but not by endothelia cells (4). Other studies have demonstrated that VM levels are associated with a poor prognosis in certain tumor patients $(4,38-40)$. In the current study, we confirmed $\mathrm{VM}$ in pancreatic cancer tissues and cell lines, even though we did not provide patient survival data. In the 117 cases of pancreatic cancer tissues in this study, VM was shown to be expressed in $71.79 \%$ (84/117) of pancreatic cancer cases.

Moreover, previous studies have shown that VM formation is associated with the expression of particular genes, such as VE-cadherin, EphA2, MMP-2 and MMP-9. VE-cadherin belongs to the cadherin family and is specifically expressed in endothelial cells. VE-cadherin is a transmembrane protein and functions to mainly mediate adhesion between cells (41), while EphA2 is a tyrosine kinase receptor and can regulate angiogenesis. VE-cadherin protein is highly expressed in high-grade malignant melanoma cells, but is not expressed in low-grade malignant melanoma cells (41). Inhibition of VE-cadherin expression using thiosulfate-modified oligonucleotides blocks vasculogenic mimicry formation in high-grade malignant melanoma (13). Similarly, immunofluorescence staining showed that the tube-like network channels in vitro expressed phosphorylated tyrosine kinase and EphA2 proteins, whereas tyrosine kinase inhibitor and/or knockdown of EphA2 expression suppressed CM formation (15). VE-cadherin co-localizes with EphA2 at areas of cell-cell contact and directly interact during VM (14). Furthermore, matrix metalloproteinases are a group of zinc-dependent endopeptidases that degrade extracellular matrix. Seftor et al (19) reported that the expression of MMP-2, MMP-9, MMP-14 and tumor cell surface laminin receptor is significantly increased in high-grade invasive melanoma tissues. Activated MMP decomposition can cleave laminin into multiple short-chains, promoting the formation of VM. Sood et al (21) demonstrated that the expression of MMP-1, MMP-2, MMP-9, MT1-MMP and laminin is significantly increased in 3D culture of invasive ovarian cancer cells. Interestingly, they showed that the metalloproteinase inhibitor Metastat in the 3D culture could inhibit VM. Transfection with extracellular matrix metalloproteinase CD147 CDNA into low invasive ovarian cancer cells leads to the formation of VM in 3D culture. In addition, MMP-2 and MMP-9 protein levels and their activity are significantly increased, and this promoted formation of vasculogenic mimicry (6). Taken together, these proteins promote VM formation in different tumor cell lines and inhibition or knockdown of these proteins suppresses VM formation. Indeed, our current study also confirmed these studies ex vivo.

Classic tumor angiogenesis theory believes that tumor lesions greater than 1-2 mm will activate and promote endothelial cells to build new blood vessels for tumor cell growth. Thus, tumor growth, invasion, metastasis and recurrence are dependent on the blood supply $(2,3)$. Anti-angiogenesis therapy could be a useful treatment strategy for cancer therapy. The traditional anti-angiogenesis therapies mainly target vascular endothelial cells. Liu et al (42) showed that melanin anti-angiogenesis therapy has little effect on a patient's prognosis. Van der Schaft et al (32) reported that angiogenesis inhibitors (Anginex, TNP-470 and endostatin) inhibit angiogenesis, but cannot prevent melanoma cells forming VM. In this regard, VM formation may provide a reasonable explanation for ineffective clinical anti-angiogenesis therapy against human cancers. In the current study, we assessed ginsenoside $\mathrm{Rg} 3$ as an alternative strategy to inhibit VM formation for adjuvant treatment of pancreatic cancer. Indeed, previous studies reported by Shin et al (43) and Xu et al (44) showed that Ginsenoside Rg3 was able to inhibit MMP-9 expression in cultured mammalian and ovarian cancer cells and metastasis of ovarian cancer cells. Chen et al (45) revealed that Ginsenoside Rg3 inhibits MMP-2 expression in a human lung adenocarcinoma cell line. Our current study showed that Ginsenoside $\mathrm{Rg} 3$ treatment reduced tumor xenograft weigh and tumor size in vivo in nude mice. This was associated with the inhibition of VM formation and downregulation of VE-cadherin, EphA2, MMP-9 and MMP-2 expression.

In summary, our current study demonstrated increased VM formation in pancreatic cancer tissues when compared to benign pancreatic diseases. VM formation was associated with the expression of cell adhesion and MMP proteins. Furthermore, ginsenoside Rg3 effectively inhibited VM formation of pancreatic cancer cells in vivo and in vitro. At the gene level, ginsenoside Rg3-inhibited VM formation was associated with the downregulation of VE-cadherin, EphA2, MMP-9 and MMP-2 protein expression. Thus, our present study provides preliminary evidence for the use of $\operatorname{Rg} 3$ for the treatment of pancreatic cancer.

\section{Acknowledgements}

We would like to thank Dr Liwei Xie and Dr Qiaoqiao Hua of The Second Affiliated Hospital, Wenzhou Medical University (Wenzhou, China) and The Pathology Department of First Affiliated Hospital, Zhejiang University School of Medicine (Hangzhou, China) for providing help in immunohistochemistry. We are grateful for funding support from: the Administration of Traditional Chinese Medicine of Zhengjing Province, China (grant no. 2011ZZ010), Zhejiang Provincial Science Fund for Distinguished Young Scholars (grant no. LR12H280001) and the National Natural Science Foundation of China (grant no. 81173606).

\section{References}

1. Saif M, Lee Y and Kim R: Harnessing gemcitabine metabolism: a step towards personalized medicine for pancreatic cancer. Ther Adv Med Oncol 4: 341-346, 2012.

2. Folkman J: Angiogenesis in cancer, vascular, rheumatoid and other disease. Nat Med 1: 27-31, 1995.

3. Bergers $\mathrm{G}$ and Benjamin LE: Tumorigenesis and the angiogenic switch. Nat Rev Cancer 3: 401-410, 2003.

4. Maniotis AJ, Folberg R, Hess A, Seftor EA, Gardner LM, Pe'er J, Trent JM, Meltzer PS, et al: Vascular channel formation by human melanoma cells in vivo and in vitro: vasculogenic mimicry. Am J Pathol 155: 739-752, 1999.

5. Wang W, Lin P, Han C, Cai W, Zhao X and Sun B: Vasculogenic mimicry contributes to lymph node metastasis of laryngeal squamous cell carcinoma. J Exp Clin Cancer Res 60: 2-9, 2010.

6. Millimaggi D, Marl M, D'Ascenzo S, Giusti I, Pavan A and Dolo V: Vasculogenic mimicry of human ovarian cancer cells: Role of CDI47. Int J Oncol 35: 1423-1428, 2009.

7. Clemente M, Pérez-Alenza MD, Illera JC, Illera JC and Peña L: Histological, immunohistological, and ultrastructural description of vasculogenic mimicry in canine mammary cancer. Vet Pathol 47: 265-274, 2010

8. Cai XS, Jia YW, Jiong M and Tang RY: Tumor blood vessels formation in osteosarcoma: vasculogenesis mimicry. Chin J Med 117: 94-98, 2004. 
9. Yue WY and Chen ZP: Does vasculogenic mimicry exist in astrocytoma? J Histochem Cytochem 539: 997-1002, 2005.

10. Sun W, Fan YZ, Zhang WZ and Ge CY: A pilot histomorphology and hemodynamic of vasculogenic mimicry in gallbladder carcinomas in vivo and in vitro. J Exp Clin Cancer Res 46 $2-11,2011$.

11. Yue WY and Chen ZP: Vasculogenic mimicry - potential target for tumor therapy. Ai Zheng 25: 914-916, 2006 (In Chinese).

12. Shirakawa K, Kobayashi H, Heike Y, Kawamoto S, Brechbiel MW, Kasumi F, Iwanaga T, et al: Hemodynamics in vasculogenic mimicry and angiogenesis of inflammatory breast cancer xenograft. Cancer Res 62: 560-566, 2002.

13. Hendrix MJ, Seftor EA, Meltzer PS, Gardner LM, Hess AR, Kirschmann DA, Schatteman GC, et al: Expression and functional signiicance of VE-cadherin in aggressive human melanoma cells: role in vasculogenic mimicry. Proc Natl Acad Sci USA 98: 8018-8023, 2001.

14. Hess AR, Seftor EA, Gruman LM, Kinch MS, Seftor RE and Hendrix MJ: VE-cadherin regulates EphA2 in aggressive melanoma cells through a novel signaling pathway: implications for vasculogenic mimicry. Cancer Biol Ther 5: 228-233, 2006.

15. Hess AR, Seftor EA, Gardner LM, Carles-Kinch K, Schneider GB, Seftor RE, Kinch MS, et al: Molecular regulation of tumor cell vasculogenic mimicry by tyrosine phosphorylation: role of epithelial cell kinase (Eck/EphA2). Cancer Res 61: 3250-3255, 2001.

16. Margaryan NV, Strizzi L, Abbott DE, Seftor EA, Rao MS, Hendrix MJ and Hess AR: EphA2 as a promoter of melanoma tumorigenicity. Cancer Biol Ther 8: 279-288, 2008.

17. Hess AR, Margaryan NV, Seftor EA and Hendrix MJ: Deciphering the signaling events that promote melanoma tumor cell vasculogenic mimicry and their link to embryonic vasculogenesis: role of the Eph receptors. Dev Dyn 236: 3283-3296, 2007.

18. Seftor RE, Seftor EA, Koshikawa N, Meltzer PS, Gardner LM, Bilban M, Stetler-Stevenson WG, et al: Cooperative interactions of laminin 5 gamma 2 chain, matrix metalloproteinase-2, and membrane type-1-matrix/metalloproteinase are required for mimicry of embryonic vasculogenesis by aggressive melanoma. Cancer Res 61: 6322-6327, 2001.

19. Seftor RE, Seftor EA, Kirschmann DA and Hendrix MJ Targeting the tumor microenvironment with chemically modified tetracyclines: inhibition of laminin 5 gamma 2 chain promigratory fragments and vasculogenic mimicry. Mol Cancer Ther 1: 1173-1179, 2002.

20. Hess AR,SeftorEA, Seftor RE and Hendrix MJ: Phosphoinositide 3-kinase regulates membrane type 1-matrix metalloproteinase (MMP) and MMP-2 activity during melanoma cell vasculogenic mimicry. Cancer Res 63: 4757-4762, 2003.

21. Sood AK, Fletcher MS, Cofin JE, Yang M, Seftor EA, Gruman LM, Gershenson DM, et al: Functional role of matrix metalloproteinases in ovarian tumor cell plasticity. Am J Obstet Gynecol 190: 899-909, 2004.

22. Yue PY, Wong DY and Wu PK: The angiosuppressive effects of 20(R)-ginsenoside Rg3. Biochem Pharmacol 72: 437-445, 2006.

23. Han J, Hao F, Hao F, An Y, Xu Y, Xiaokaiti Y, Pan Y, et al: Ginsenoside $\mathrm{Rg} 3$ attenuates cell migration via inhibition of aquaporin 1 expression in PC-3M prostate cancer cells. Eur J Pharmacol 683: 27-34, 2012.

24. Kim JW, Jung SY, Kwon YH, Lee JH, Lee YM, Lee BY and Kwon SM: Ginsenoside $\operatorname{Rg} 3$ attenuates tumor angiogenesis via inhibiting bioactivities of endothelial progenitor cells. Cancer Biol Ther 13: 504-515, 2012.

25. Zhang C, Liu L, Yu Y, Chen B, Chen B, Tang C and Li X: Antitumor effects of ginsenoside $\mathrm{Rg} 3$ on human hepatocellular carcinoma cells. Mol Med Rep 5: 1295-1298, 2012.

26. Lee CK, Park KK, Chung AS and Chung WY: Ginsenoside $\mathrm{Rg} 3$ enhances the chemosensitivity of tumors to cisplatin by reducing the basal level of nuclear factor erythroid 2-related factor 2-mediated heme oxygenase-1/NAD $(\mathrm{P}) \mathrm{H}$ quinone oxidoreductase-1 and prevents normal tissue damage by scavenging cisplatin-induced intracellular reactive oxygen species. Food Chem Toxicol 50: 2565-2574, 2012.
27. Liu JP, Lu D, Nicholson RC, Li PY and Wang F: Toxicity of a novel anti-tumor agent 20(S)-ginsenoside Rg3: a 26-week intramuscular repeated administration study in Beagle dogs. Food Chem Toxicol 49: 1718-1727, 2011

28. Yuan HD, Quan HY, Zhang Y, Kim SH and Chung SH: 20(S)-Ginsenoside Rg3-induced apoptosis in HT-29 colon cancer cells is associated with AMPK signaling pathway. Mol Med Rep 3: 825-831, 2010.

29. Chen XP, Qian LL, Jiang H and Chen JH: Ginsenoside Rg3 inhibits CXCR4 expression and related migrations in a breast cancer cell line. Int J Clin Oncol 16: 519-523, 2011.

30. Greenberg E, Hershkovitz L, Itzhaki O, Hajdu S, Nemlich Y, Ortenberg R, Gefen N, et al: Regulation of cancer aggressive features in melanoma cells by microRNAs. PLoS One 6: e18936, 2011.

31. Folkman J: Tumor angiogenesis therapeutic implications. $\mathrm{N}$ Engl J Med 285: 1182-1186, 1971

32. Van der Schaft DW, Seftor RE, Seftor EA, Hess AR, Gruman LM, Kirschmann DA, Yokoyama Y, et al: Effects of angiogenesis inhibitors on vascular network formation by human endothelial and melanoma cells. J Natl Cancer Inst 96: 1473-1477, 2004.

33. Chen LX, He YJ, Zhao SZ, Wu JG, Wang JT, Zhu LM, Lin TT, et al: Inhibition of tumor growth and vasculogenic mimicry by curcumin through downregulation of the EphA2/PI3K/MMP pathway in a murine choroidal melanoma model. Cancer Biol Ther 11: 229-235, 2011.

34. Wang HB. Lin YC, Zeng DE, Lin W, Hong CQ, Lin WZ and Chen JY: Inhibitory effect of ginsenoside Rg3 on the tube-like structure formation in human nasopharyngeal carcinoma HNE-1 cell line in vitro. Zhonghua Zhong Liu Za Zhi 32: 739-742, 2010 (In Chinese).

35. Sun B, Zhang S, Zhang D, Yin X, Wang S, Gu Y and Wang Y: Doxycycline influences microcirculatin patterns in B16 melanoma. Exp Biol Med (Maywood) 232: 1300-1307, 2007.

36. Guo HC, Bu HQ, Luo J, Wei WT, Liu DL, Chen H, Tong HF, et al: Emodin potentiates the antitumor effects of gemcitabine in PANC-1 pancreatic cancer xenograft model in vivo via inhibition of inhibitors of apoptosis. Int J Oncol 40: 1849-1857, 2012.

37. Ruf W, Seftor EA, Petrovan RJ, Weiss RM, Gruman LM, Margaryan NV, Seftor RE, et al: Differential role of tissuefactor pathway inhibitors 1 and 2 in melanoma vasculogenic mimicry. Cancer Res 63: 5381-5389, 2003.

38. Kirschmann DA, Seftor EA, Hardy KM, Seftor RE and Hendrix MJ: Molecular pathways: vasculogenic mimicry in tumor cells: diagnostic and therapeutic implications. Clin Cancer Res 18: 2726-2732, 2012.

39. Hendrix MJ, Seftor EA, Hess AR and Seftor RE: Vasculogenic mimicry and tumour-cell plasticity: lessons from melanoma. Nat Rev Cancer 3: 411-421, 2003.

40. Folberg R, Arbieva Z, Moses J, Hayee A, Sandal T, Kadkol S, Lin AY, et al: Tumor cell plasticity in uveal melanoma: microenvironment directed dampening of the invasive and metastatic genotype and phenotype accompanies the generation of vasculogenic mimicry patterns. Am J Pathol 169: 1376-1389, 2006.

41. Fan YZ and Sun W: Molecular regulation of vasculogenic mimicry in tumors and potential tumor-target therapy. World J Gastrointest Surg 2: 117-127, 2010

42. Liu R, Cao Z, Tu J, Pan Y, Shang B, Zhang G, Bao M, et al: Lycorine hydrochloride inhibits metastatic melanoma cell-dominant vasculogenic mimicry. Pigment Cell Melanoma Res 25: 630-638, 2012.

43. Shin YM, Jung HJ, Choi WY and Lim CJ: Antioxidative, anti-inflammatory, and matrix metalloproteinase inhibitory activities of 20(S)-ginsenoside $\operatorname{Rg} 3$ in cultured mammalian cell lines. Mol Biol Rep 40: 269-279, 2013.

44. Xu TM, Cui MH, Xin Y, Gu LP, Jiang X, Su MM, Wang DD, et al: Inhibitory effect of ginsenoside $\operatorname{Rg} 3$ on ovarian cancer metastasis. Chin Med J 121: 1394-1397, 2008.

45. Chen MW, Ni L, Zhao XG and Niu XY: The inhibition of 20(R)-ginsenoside Rg3 on the expressions of angiogenesis factors proteins in human lung adenocarcinoma cell line A549 and HUVEC304 cell. Zhongguo Zhong Yao Za Zhi 30: 357-360, 2005 (In Chinese) 